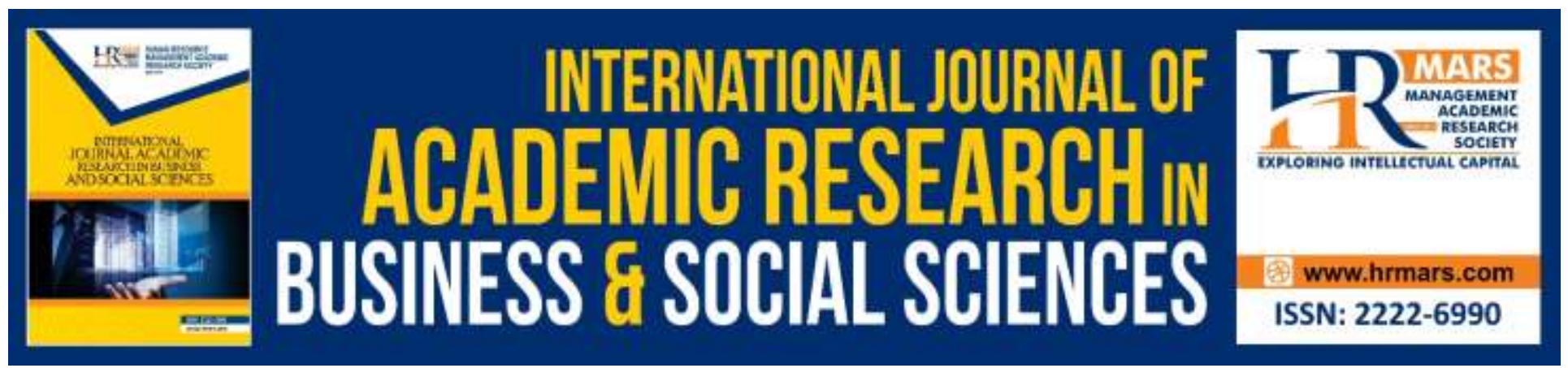

\title{
A Rollercoaster Ride of Emotions: Investigating Learning Challenges in a Doctoral Learning Journey
}

\author{
Hamidah Mohd Ismail, Faizah Abd Majid, Izaham Shah Ismail
}

To Link this Article: http://dx.doi.org/10.6007/IJARBSS/v9-i13/6260

DOI: $10.6007 /$ IJARBSS/v9-i13/6260

Received: 21 March 2019, Revised: 19 May 2019, Accepted: 24 July 2019

Published Online: 20 August 2019

In-Text Citation: (Ismail, Majid, \& Ismail, 2019)

To Cite this Article: Ismail, H. M., Majid, F. A., \& Ismail, I. S. (2019). A Rollercoaster Ride of Emotions:

Investigating Learning Challenges in a Doctoral Learning Journey. International Journal of Academic Research in Business and Social Sciences, 9(13), 262-269.

Copyright: (C) 2019 The Author(s)

Published by Human Resource Management Academic Research Society (www.hrmars.com)

This article is published under the Creative Commons Attribution (CC BY 4.0) license. Anyone may reproduce, distribute, translate and create derivative works of this article (for both commercial and non-commercial purposes), subject to full attribution to the original publication and authors. The full terms of this license may be seen

at: http://creativecommons.org/licences/by/4.0/legalcode

Special Issue: Revolutionizing Education: Challenges, Innovation, Collaboration, 2019, Pg. 262 - 269 http://hrmars.com/index.php/pages/detail/IJARBSS

JOURNAL HOMEPAGE

Full Terms \& Conditions of access and use can be found at http://hrmars.com/index.php/pages/detail/publication-ethics 


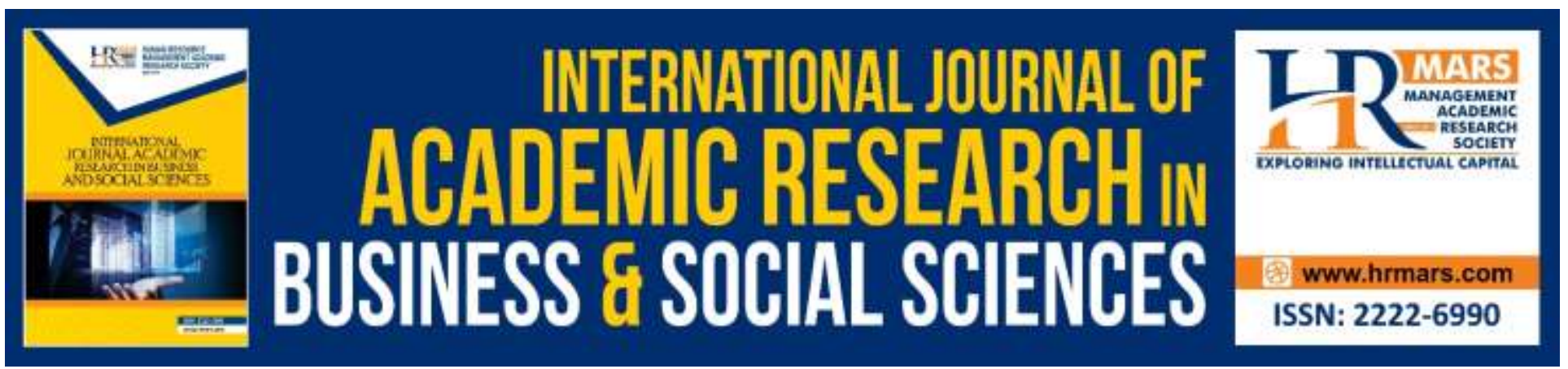

\title{
A Rollercoaster Ride of Emotions: Investigating Learning Challenges in a Doctoral Learning Journey
}

\author{
Hamidah Mohd Ismail, Faizah Abd Majid, Izaham Shah Ismail \\ Universiti Teknologi MARA, Malaysia
}

\begin{abstract}
Although there has been a substantial increase in the number of research students enrolled in public higher learning institutions in Malaysia, the high attrition rate amongst doctoral students is quite alarming. Various research efforts have been carried out to investigate this phenomenon; however, most of the studies were focused solely on supervision. Even less is known about the challenges that research students in Malaysia face during their doctoral learning journey and how they cope with these challenges. This study examined the learning challenges that research students experienced during their doctoral learning journey and how they managed to overcome the challenges. This qualitative study involved an extensive collection of time- and context-sensitive data and emphasized on giving participants a personal voice. Snowball sampling was used and a total of eight participants were involved in this study. Four stages of data collection generated rich data from lengthy interviews and provided opportunities for re-interviewing the same participants all over again. Three types of interviews were utilised, and necessary steps were taken to ensure trustworthiness was established in this research. Based on the research findings, three broad categories of learning challenges were identified namely supervision, academic and psychological. Academic challenges were most profound in their learning in which knowledge creation and conceptualization being the most challenging skills whilst psychological issues were the least challenging. This study introduced a fresh perspective to the literature on research students, which has been dominated by investigation into the supervision process.
\end{abstract}

\section{Introduction}

There has been a substantial increase in the number of research students enrolled in public higher learning institutions in Malaysia. The number of enrolments increased from 17,718 in 2010 to 31,014 in 2014 (Ministry of Higher Education, 2011, 2016). This accounted to about 40\% increase in enrolment over a span of 5 years. The drastic increase is aligned to the National Higher Education Strategic Plan 2020 in which the Ministry of Higher Education (MOHE) has targeted a total of 60000 $\mathrm{PhD}$ candidates by the year 2020. Although an increase in the number of PhD enrolment seems to support the nation's aspiration to elevate human capital, one important issue still needs to be 
addressed in order to achieve such target; that is the high attrition rate amongst research students. In the article "3 out of 10 doctoral students drop out" (2011), the New Straits Times reported that slightly more than $30 \%$ of research students in Malaysia dropped out due to various personal and academic reasons. The newspaper report further stated that the two most common reasons given were work commitments and family problems.

Most often research students start their PhD thinking of the end product, i.e. the thesis. However, in many cases the high hope that starts their PhD journey soon fades off into the mysterious background of a volatile journey that can be very frustrating to many. Batchelor and Di Napoli (2006) describe this volatile journey as a voyage of vulnerability where research students are thrown into the unknown sea of knowledge and constantly battle with conflicts as they seek new knowledge in the process of learning, unlearning and re-learning. This becomes a repetitive process of trial and error and often results in research students experiencing difficulties or "stuckness" (p.14). When a PhD candidate embarks on a doctoral journey, he or she will naturally start with a question that calls for a research into the phenomenon. However, education can be disruptive in nature. The student may end up being in the 'wasted first year', trying to find one that is acceptably a contribution to the field of knowledge and addresses the gap in research (Zuram, 2005). As a matter of fact, there have been many online discussions amongst research students seeking advice on the breaking point and many have lamented on the question of when to throw in the 'PhD towel'. It is common to hear research students refer to situations like 'PhD depressions', 'stuck in second gear', 'postgrad blues', 'stuck in an infinite loop', etc. Previous literature had consistently shown that research students' incompetence in performing independent research was a major contribution to high attrition rates amongst research students from the field of social sciences (Lovitts \& Nelson, 2000). This augurs well with the concept of "doctorateness" in which Park (2007) used to discriminate between a PhD degree and other degrees. "Doctorateness" is described as the ability of a student to exhibit episteme and think like a researcher (Trafford \& Leshem, 2009) and an independent scholar (McKenna, 2006). Hence, it is important that research students incorporate the right way of thinking and practicing in order to achieve some level of doctorateness in order to succeed (Entwisle, 2004).

This paper is part of a larger study that investigated the learning process of research students in Education Faculties from several public higher learning institutions in Malaysia. Specifically, this paper discussed challenges that research students experienced during their doctoral learning journey. Based on their lived experiences on the phenomena, a descriptive understanding of the types of challenges were identified and analyzed to provide a rich description of the challenges and narrate how these students managed to overcome their challenges. Previous studies on doctoral learning journey often described research students' experiences in a form of 'metaphorical journey' (Perera, 2005; Vilkinas, 2005). Research students' used metaphors such as 'voyages', 'threshold crossings', 'the blind adrenalin rush', 'rollercoaster rides' to describe their challenges throughout the learning journey with anecdotes replicating their many trials and tribulations during the phases of the journey. Based on the findings, issues that were commonly discussed as challenges involved three broad categories; namely, supervisory problems, academic problems, as well as psychological problems. 
Supervision appeared to be the dominant theme in most literature on doctoral learning challenges. It is reported to be a critical factor in ensuring research students' successful completion (Lovitts, 2001) and doctoral education quality (Morgan \& Ryan, 2003). As such, lack of effective supervision contributed to low completion rates and lack of enthusiasm for research (Haksever \& Manisali, 2000). Lack of commitment, emotional support and research interests by the supervisor were idenfied as prime challenges amongst research students. Meanwhile, academic problems emerged when research students with non-research background embarked on postgraduate research studies. This caused major changes in various areas such as styles of work, intellectual, technical and organizational skills. Findings from various research reported academic problems such as difficult to identify a research problem and decide on a research topic as well as methodological difficulties (Lovitts, 2001). Intrapersonal and interpersonal problems were part of psychological factors that could impede research students' successful completion of their studies. Findings from previous research also reported challenges such as feelings of isolation, boredom, frustration, and potential loss of enthusiasm as well as procrastination and perfectionism that impeded students' motivation throughout their learning journey.

\section{Method}

In order to investigate what learning challenges that research students faced during their doctoral learning journeys, a multiple-case study research was employed as it involved more than one single case and the cases were further examined to understand the similarities and differences between the cases. This 'comprehensive research strategy' (Yin, 2016, p.14) allowed a detailed account of the lived experiences of the research students throughout their doctoral learning journeys. The study was conducted at several public learning institutions in Malaysia where four research participants were from research universities, two were from comprehensive universities and the remaining two from focused universities. Utilizing snowball sampling, the first three key participants who had met the criteria were established for participation in this study. During the interview sessions with the three participants, each of them was asked to refer another participant that they would find suitable to participate in this study. Even without full knowledge of the population, snowball sampling had provided access to more quality participants, as relevant leads were only identified at each sampling step.

Three main stages of data collection by means of three types of interviewing were utilized in this study. Stage one involved storytelling where semi-structured interviews were conducted with the participants on an individual basis. The average length of the storytelling sessions was 55 minutes, with a range from 35 minutes to 90 minutes. Meanwhile in stage two, stimulated recall interview allowed further clarification, elaboration and comments on the topics raised in the storytelling stage. The third stage of data collection involved semi-structured interviews that were conducted within six months after the second stage of data collection. A set of semi-structured interview guidelines was composed to provide a framework or checklist for developing individual semi-structured interview guides. These guidelines presented the issues which were further investigated in each individual interview. 
Trustworthiness was enhanced in this study by adopting the process of intercoder reliability check. The process of intercoder reliability check included developing coding scheme with an initial set of several dozen codes with definitions grouped into categories. Then random interview transcript was selected and followed by coding the first ten pages of the transcript. This was based on the amount of text recommended and as a general rule, ten percent of the set of documents is suggested (Campbell, Quincy, Osserman, \& Pedersen, 2013). A more experienced coder was engaged to go over the coding and results were then compared and discussed whenever there were discrepancies and confusion. The code scheme was then refined until both parties were satisfied with the level of intercoder reliability.

Qualitative analyses were performed on the data collected from all three stages of interviewing. In this study, multiple case studies involved the collection and analysis of data that was retrieved from several cases. Contextual variables were also investigated from data that surfaced during the three stages of interviews with all cases. Once data was retrieved from all eight participants and completed, cross-case analysis was then conducted to build constructs across the cases in order to seek explanations and to uncover various perspectives of the central phenomena.

\section{Results and Discussion}

Rich descriptions were captured from research students' lived experience on various challenges that they faced throughout their doctoral learning journeys. Comparison of their stories revealed that the students possessed distinct personalities possessing diverse perceptions of their learning contexts. However, they share similarities in theoretical and methodological preparation for their PhD studies. Hence the findings revealed that the research students' theoretical and methodological preparation had a significant influence on their overall doctoral learning experience. In addition, the students who had obtained their master's degrees through coursework showed a strong tendency to depend on their supervisors in the early stages of their candidature, although they gradually developed a higher level of independence when they understood that they were expected to be autonomous in learning. Contrastingly, students who had completed their master's degrees by full research mode demonstrated a preference for independence and were able to keep a balance between dependence and independence.

Findings from this study also suggested that academic problems seemed to have affected research students' style of work, intellectual, technical and organizational skills. All eight research students reported that knowledge creation and conceptualization were the two biggest challenges that they faced when doing their research work. One research student clarified that knowledge creation was something he struggled during his doctoral learning journey as he narrated his difficulties trying to justify what exactly was his original contribution to his field of study. This was also accounted by another student when she had difficulties finding an answer when asked by her supervisor how her research could contribute to her field. Findings by Kiley and Wisker (2009) in their research supported these findings as they identified knowledge creation as one of the major threshold concepts that research students face during their doctoral learning journey. 
Another common academic problem that research students faced was conceptualization. Martin, Cohen and Champion (2013) describe it as the "process of translating concepts into theories...the mental framework we construct with and about a set of related concepts" (p. 5). Based on research students' accounts working on their research topics, all students had difficulties, but in varying degrees, refining research ideas that they have obtained from literature review into specific terms. The students also faced problems interpreting the new knowledge and merging them into their study. Comparatively, conceptualization was also another threshold concept that was identified in Kiley and Wisker's (2009) research findings.

Looking further at academic problems faced by the research students, most of the research students lacked research background and academic writing skills needed to achieve the level of doctorateness. Interestingly however, based on their descriptions the students were aware of their valuable skills and abilities that they possessed and used these skills and abilities to manage their shortcomings. Challenges that revolved around their lack of research skills were also addressed quite similarly by some research students. Research methodology and analyzing data were two of the areas that they had described as most troublesome. Despite the challenges, the students worked hard and managed to complete their research proposals and developed various new research skills as they audited topics and attended seminars and training sessions throughout their learning journey. Cultural values also remained a challenge for the participants as it was difficult for them to put an argument in writing.

In terms of supervision issues, the research students had different experiences which were more personalized and contextualized. Maintaining good relationships with their supervisors was a challenge that five research students accounted for. However, as adult learners, the research students were able to iron out this challenge although in a few cases it was resolved only at the later part of their learning journey. Emotional support was also important to some of the research students. This is supported by Merriam and Tisdel (2016) who specified that although research students are self-directed adult learners, they still require support and guidance especially in the early stages of their doctoral learning journey.

Psychological issues had the least number of challenges that research students identified. While some participants kept their personal challenges private, a few others were seen to be struggling more openly. The expectation of completing their scholarships within three years posed difficulties for them and added more pressure to complete their research with the given time frame. However, all research participants lamented that it was very challenging to keep themselves motivated, particularly at the beginning stage of their research journey. This could be related to the challenges on conceptualization as they began their literature review.

\section{Conclusion}

This study aimed to understand the learning processes of research students of education in Malaysian public universities with a focus on learning challenges that they had to endure. The research methodology focused on examining the phenomenon from the learners' perspective within the context. The findings of within-case of the interview data lend support to the study, which challenge the stereotyped views of research students and which argue for a contextualized approach to 
investigate the challenges faced by the students. As second language learners, some of the research students shared similar problems that other students might have encountered, such as difficulties caused by limited English language proficiency and challenges of research tasks that required critical and analytical skills.

The study revealed that the major causes of their problems in $\mathrm{PhD}$ research were not language but their knowledge of the field and research methodology. In other words, the students' theoretical and methodological preparation were two most important influence on their doctoral learning experience. Students who were less experienced in researching and were doing a PhD in a field different from their previous academic studies were likely to encounter problems of theoretical deficiency, insufficient methodological knowledge, and underdeveloped research skills. These students tended to lack confidence in both themselves and the quality of their research.

Contrastingly, students who were experienced in researching and were doing a PhD based on the research done for their previous academic degrees showed more confidence in both their theoretical knowledge of the field and research competence. Nevertheless, these experienced research students also indicated the need to further develop their methodological knowledge and research skills, especially for data analysis. Therefore, methodological issues were observed to be the major concern shared by both experienced and less experienced research students. To cope with methodological difficulties, the research students identified the need to learn more about research methodology and further develop their research skills. For the students who lacked prior knowledge of their field of interest, they also articulated the need to build up their theoretical base. In line with their needs, the participants applied several learning strategies to facilitate their learning and problem-solving.

Based on the findings of this study, it is suggested that research students need to apply successful learning strategies when facing learning challenges in order to facilitate their self-teaching and problem solving and ultimately attain their learning goals. Supervisors, as experienced researchers, should be able to help their students to improve learning efficiency by suggesting effective learning strategies, in addition to routine supervision. Additionally, formal methodological training is desirable for research students and that institutions could provide methodological training as a form of learning assistance and encourage students to attend it voluntarily in the initial stages of their study or when the need arises.

Despite its limitations, this study extends the research on learning challenges to the context of doctoral students' learning. Furthermore, systematic examination of the students' learning challenges casts light on the doctoral learning process and introduced a fresh perspective to the literature on doctoral students, which has been dominated by investigation into the supervision process. Lastly, this study provides an in-depth understanding of the learning processes of research students studying in Malaysian universities. Nevertheless, to advance the understanding of the students' autonomy, additional investigation into their learning strategies to overcome the challenges is necessary. 
INTERNATIONAL JOURNAL OF ACADEMIC RESEARCH IN BUSINESS AND SOCIAL SCIENCES

Vol. 9, No. 13, Special Issue: Revolutionizing Education: Challenges, Innovation, Collaboration., 2019, E-ISSN: 2222-6990 @ 2019 HRMARS

\section{References}

Batchelor, D. \& Napoli, D. R. (2006). The doctoral journey: Perspectives. Educate, 6(1), 13-24.

Campbell, J. L., Quincy, C., Osserman, J. \& Pedersen, O. K. (2013). Coding in-depth semi-structured interviews: Problems of unitization and inter-coder reliability and agreement. Sociological Methods and Research, 42(3), 294-320.

Entwistle, N. (2004). Teaching-learning environment to support deep learning in contrasting subject areas, Paper presented at Staffordshire University, 29 June, Stafford.

Haksever, A. M., \& Manisali, E. (2000). Assessing supervision requirements of PhD students: The case of construction management and engineering in the UK. European Journal of Engineering Education, 25(1), 19-32.

Kiley, M. \& Wisker, G. (2009) Threshold concepts in research education and evidence of threshold crossing. Higher Education Research \& Development, 28(4), 431-441.

Lovitts, B. E. (2001). Leaving the ivory tower: The causes and consequences of departure from doctoral study. Lanham, MD: Rowman \& Littlefield Publishers, Inc.

Lovitts, B. E., \& Nelson, C. (2000). The hidden crisis in graduate education: Attrition from Ph.D. programs. Academe: Bulletin of the AAUP, 86(6), 44-50.

Martin, R., Cohen, J. W. \& Champion, D. R. (2013). Conceptualization, operationalization, construct validity, and truth in advertising in criminological research. Journal of Theoretical \& Philosophical Criminology, 5(1), 1-38.

Martin, Y. M., Maclachlan, M., \& Karmel, T. (2001). Postgraduate completion rates. Canberra: Higher Education Division, Department of Education, Training and Youth Affairs.

McKenna, H. (2006). Nursing theories and models. Routledge.

Merriam, S. B. \& Tisdell, E. J. (2016). Qualitative research: A guide to design and implementation. (4th ed.). San Francisco, CA: Jossey-Bass

Ministry of Education Malaysia, (2015). Quick facts 2015. Educational Planning and Research Division, Malaysia Educational Statistics.

Morgan, W., \& Ryan, M. (2003). Rendering an account: An open-state archive in postgraduate supervision. Higher Education Research and Development, 22(1), 77-90.

Park, C. (2007). Redefining the Doctorate. York: The Higher Education Academy.

Perera, S. (2005). Plunge into the Deep End. In T. Vilkinas (Ed), The Thesis Journey: Tales of personal triumph, (pp. 27-30). Frenchs Forest: Pearson.

Thorne, L. E. (1999). Perspectives on the purposes, processes and products of doctorates: Towards a rich picture of doctorates. (Doctoral dissertation, Middlesex University).

Trafford, V. \& Leshem, S. (2009). Doctorateness as a threshold concept. Innovations in Education and Teaching International. Special issue: Embracing Contraries in Research on Doctoral Education, 46(3), 305-316.

Vilkinas, T. (2005). The supervisor role as a manager of the Ph.D. journey. In P. Green (Ed.), Supervising postgraduate research: Contests and processes, theories and practices (pp. 163177). Melbourne, Australia: RMIT University Press.

Yin, R. K. (2016). Qualitative research from start to finish (2nd ed.). New York: The Guilford Press

Zuram, D. (2005). PhDs: What they don't tell you. Retreived from www. FindAPhD.com 